\title{
The potential of urban distributed solar energy in transition economies: The case of Beirut city
}

\section{Highlights}

- The potential for distributed rooftop solar technology in Beirut is estimated at the building level.

- The effects of economic and non-economic factors on solar photovoltaic (PV) adoption decisions are analyzed using a probabilistic choice model.

- The impact of various incentive policies and societal factors affecting solar PV adoption is investigated, with implications for policy makers.

- Subsidy removal increases adoption rates, partly compensating for weak non-financial incentives

- The Lebanese government should fast-track and implement the required legal framework for distributed power generation including PV systems.

\begin{abstract}
In this paper, using Lebanon's capital, Beirut, as a case study, a methodology is proposed to assess the potential for solar photovoltaics (PV) in urban areas incorporating both economic and noneconomic factors. Utilizing a rich spatial dataset of solar irradiation augmented with electricity bills at the building level, the cost and benefit of installing rooftop PV systems for each building is estimated. Additionally, incentives and barriers for adopting those systems are investigated using a probabilistic choice model. The results show that Beirut city has a potential for distributed rooftop solar PV to be between 195 and $295 \mathrm{MWp}$. However, adoption rates are low at $0.49 \%$ and $1.23 \%$ for residential and commercial buildings, respectively, reflecting the limitation of financial incentives alone to promote the deployment of distributed renewable energy systems in transition economies. The impact of different incentive policy instruments and the role of solar PV in today's economic crisis in Lebanon is analyzed. The biggest impact was achieved through removing (or lowering) electricity tariff subsidy, although this option remains highly constrained by political calculus. We argue that the Lebanese government should fast-track and implement the required legal framework to facilitate and incentivize distributed power generation from renewable sources to promote both green energy and its financial resilience. The proposed modeling framework together with the results obtained in this study will have important implications for energy policy makers in Lebanon and other transition economies.
\end{abstract}

Keywords: Distributed solar energy, Solar energy potential, Building level analysis, Policy analysis, Transition economies

\section{Introduction}

In the past two decades, several countries have applied considerable efforts to support the adoption of small-scale renewable energy technologies (i.e. at the household level). Solar photovoltaic (PV) technology is among the most popular renewable energy technologies (RET) due to their scalability, improved performance and price decreases in recent years (Lazard, 2018). Despite 
these factors, the relatively high capital cost of PV panels and lack of public awareness remain obstacles that impede PV adoption for households, especially in transition economies that are shifting from centrally planned economies into market economies (Berjawi et al. 2017; Nwokocha et al., 2018). To overcome this issue, a variety of incentive policy instruments are used, including tax waivers, subsidies, and feed-in tariff mechanisms. However, there is limited consensus among economists and policy makers on the most efficient incentive policies (Kim, 2020; Dong 2012; Romano et al, 2017).

Like many countries in the Global South, Lebanon needs reliable, affordable and clean energy sources. The country's electricity sector has been a constant financial and political burden for its consecutive governments, with more than 40\% of Lebanon's public debt since 1992 (about \$36 billion) directly attributed to energy sector spending and subsidies (Ahmad, 2019). Despite this level of spending, people in Lebanon continue to suffer from prolonged power outages. Unmet demand, approximately at $40 \%$, is covered by expensive and polluting diesel generators (Berjawi et al., 2017) through an informal system of provision that has had serious health and societal impacts (Abi Ghanem, 2018; Shihadeh et al., 2013). In this context, RETs such as rooftop solar PVs can be a suitable solution for both on and off-grid electricity users given the abundance of solar irradiation in the Mediterranean region.

To date, Lebanon has initiated several laws and policies to promote RET deployment, resulting in 1417 solar PV projects installed prior to 2017 . Most are relatively small, with $90 \%$ of projects below $50 \mathrm{kWp}$, accounting for only $27 \%$ of total installed capacity (Amine and Rizk, 2018). This relatively modest contribution, however, highlights the rapid growth of the solar PV market in the country. In April 2019, the government committed to install a further $1 \mathrm{GW}$ of wind and solar electricity (MEW, 2019). As such, there is a growing need for an accurate estimation of the potential for solar energy in Lebanon and a comprehensive roadmap for policy makers on the most effective incentives for PV adoption.

\section{Theoretical Background}

Studies on household-level adoption of solar PV in urban areas use various approaches including interviews (Schelly, 2014), national surveys (Sigrin et al., 2017), diffusion models (Faiers and Neame, 2006) and cost/benefit analyses (Fikru, 2019). While both economic and non-economic factors (e.g. perceptions and attitudes towards solar PV panels) are important, there is a growing need for a holistic approach to estimate the solar potential that combines both types of factors, while also being tractable and useable for policy analysis. Some recent studies have tried to fill this gap in the literature by combining different data sources and accommodating different factors using government surveys, electricity billing information, PV cost and subsidies (Kaya et al., 2019), opinion surveys (Karjalainenand and Ahvenniemi, 2019), and integrated models (Al-Irsyad et al., 2019). Spatial data of solar irradiation is also important to properly estimate the potential for solar energy for different geographical regions (Sun et al., 2013). Zhang et al. (2020) used irradiation data to measure the potential of solar energy in China, combined with technical (i.e. panel efficiency) and economic (i.e. cost-benefit) factors, while Ghasemi et al. (2019) utilized spatial analysis and multi-criteria decision making. These studies utilized multifactor models with spatial solar irradiation data to measure PV potential and their analysis was carried out at a regional level. However, such macro-level analysis does not clearly identify the adoption potential in heterogeneous contexts in relation to residents (i.e. electricity consumers) and the buildings' rooftops (i.e. solar energy receivers). Given the heterogeneity of the residential and commercial buildings in metropolitan areas like Beirut, macro-level analysis would not give an accurate 
estimation of solar PV potential. Recent studies have tried to tackle this (Enongene et al., 2019), but without incorporating solar irradiation levels, which can vary between buildings. In contrast, Mohandes et al. (2019) used an agent-based simulation model to assess the potential for household PV adoption by accounting for PV cost, electricity price and the impact of different policy incentives as economic factors, and using neighborhood effect as a non-economic factor. However, they do not incorporate solar irradiation levels or electricity consumption (a major source of heterogeneity across households) and neither do they provide sufficient consideration of noneconomic factors associated with PV adoption (c.f. Abi Ghanem and Haggett, 2011; RansanCooper et al., 2020). In this paper, we study solar PV potential as a complimentary source of electricity. The proposed framework, along with building level data on electricity consumption and solar irradiation, allow us to examine the effect of different factors (e.g. electricity tariff, price and efficiency and durability of PV) on the adoption decision of households. Since we incorporate the cost and benefit of adoption decisions, our model is technology agnostic and can be used in case of an increase in the efficiency of PV or a decrease in the cost of storage. Using a probabilistic choice model, we incorporate non-economic factors (e.g. people's attitudes towards solar energy) while the role of societal factors on PV adoption is discussed. The proposed modeling framework allows for quantifying the impact of different policy incentives on PV adoption (i.e. on the solar energy diffusion speed and spread) and its implications for policy makers.

To showcase the applicability of the proposed framework, the solar energy potential of the city of Beirut is presented as a case study. In the context of Lebanon, several other studies focused on pure technical and/ or economic feasibility analyses for introducing solar PV systems at an aggregate level (e.g. Khoury et al., 2016; Najjar et al., 2012). However, this paper models the solar adoption decisions of each building in Beirut based on the cost and benefit of installing solar PV, supported by fine-grained spatial data on the characteristics of each building in Beirut (i.e. in terms of its size, function, and electricity consumption) as well as the solar irradiation amount received on the building rooftops considering their location, height and shadowing effects. Moreover, accurate cost data of the total installation price for solar PV and electricity tariffs is incorporated. Unlike studies that focus mainly on economic factors (Fikru, 2019), we can accommodate the unobserved non-economic factors (e.g. positive or negative perceptions towards solar panels) in the adoption decision using a probabilistic adoption model. Finally, the impact of different incentive policy instruments is simulated. The results of the analysis are quantitative and can be easily translated into dollar values for the cost and benefit of different policy instruments. We argue that this tool will have important implications for policy makers in the energy sector in Lebanon and across different geographical locations (e. g. Heng et al., 2020; Jung et al., 2014; Kaya et al., 2019; Pacudan, 2018).

\section{Data}

The analysis in this paper is based on a dataset of around 13,000 buildings in Beirut with partial information, out of which 2200 buildings with full building-level information were selected. The first dataset was acquired from the Council for Development and Construction (CDR) and includes a building identifier, with information on building area and height. This is matched with the building identifier from the Electricite du Liban (EDL) shapefile, allowing us to retrieve bimonthly electricity consumption data at the building level. It should be noted that the bimonthly resolution obtained is the most detailed level available since it is the rate at which meter reading and power bill collection are made in Lebanon. Power outage rationing schedules were obtained from EDL's website, which provides a real-time-hourly update (EDL, 2019a). This data was scraped, retrieving 
information about all of EDL's 68 sectors in Beirut covering all its buildings. All 13,000 buildings were matched with its relevant sector. Then, daylight and nighttime outage hours were computed by comparing each building's outage hours with the corresponding day's sunrise and sunset times (Sunrise Sunset, 2019). Their cumulative bimonthly values were then reported to match the resolution of the data on electricity bills.

From this dataset, a second dataset consisting of 2200 surveyed buildings was created. This includes, in addition to above figures, the available rooftop space for each building, the number of apartments (i.e. the number of subscribers to EDL), and building type (i.e. residential, commercial or mixed). This data was augmented with the building-level rooftop solar energy potential. Previous studies used different methods to estimate solar irradiation on buildings (Oh and Park, 2018), comparing different algorithms. In this paper, the buildings' heights and footprints were acquired from CDR and deployed to the ArcGIS software. The building shapefile and Beirut's weather-file (obtained from the Beirut International Airport), along with values of the diffuse fraction of solar radiation adapted from Sfeir (1981), were fed into the Solar Analyst tool in ArcGIS. This allowed us to simulate the monthly rooftop solar irradiation of all the buildings in the city taking into consideration inter-building overshadowing effect, as well as the weather conditions (shown in Fig. 1). These were also lumped at the bimonthly level to unify the temporal resolution in our analysis. To summarize, the studied dataset includes the available attributes for 2200 buildings, which are: bimonthly electricity consumption, bimonthly solar irradiation incorporating the overshadowing, bimonthly daylight and nighttime outage hours, as well as building heights, areas, number of apartments, number of floors, and building use.

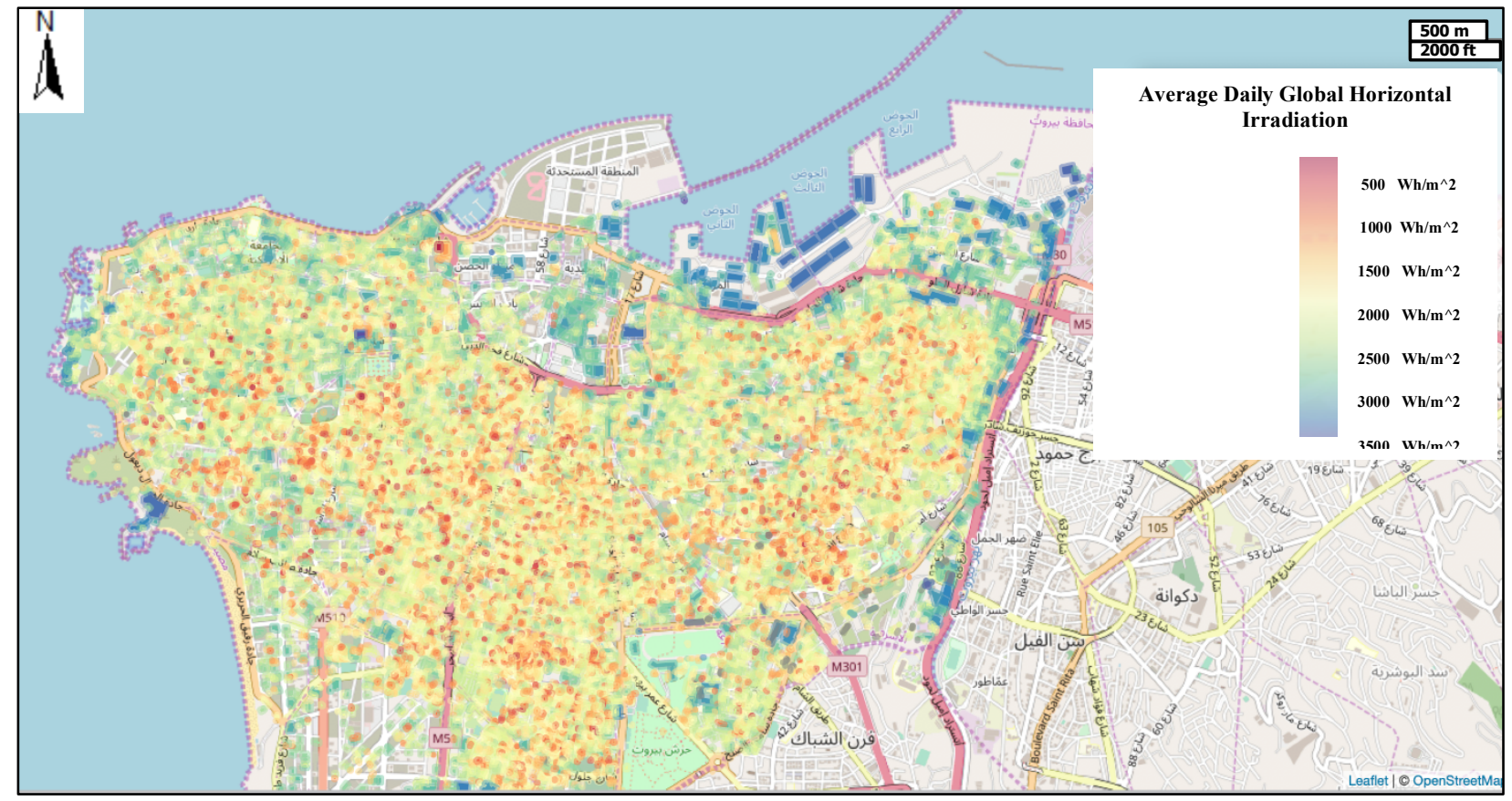

Figure 1: The simulated rooftop solar energy in Beirut

\section{Methodology}

To render results as close as possible to reality, we model the adoption decision at the building level where each building (i.e. the residents of the building) decides whether to invest in a solar PV system, given the cost and benefit of this decision for the whole building in the long term. Our 
proposed framework captures the economic aspects of investment (i.e. Net Present Value (NPV)), as well as factors such as people's general attitude towards RETs. Moreover, the disaggregate modeling framework allows us to perform policy simulation on the impact that various incentives can have on solar PV adoption and their associated costs. To simplify the analysis, the model does not include hybrid solar (Li et al., 2019) or solar with battery systems (O'Shaughnessy et al., 2018). The model's outputs are: total annual solar energy that could be generated and its per kWh cost, the potential annual savings based on consumption levels, and the NPVs of the solar PV system for both building and city levels (see Figure 2).

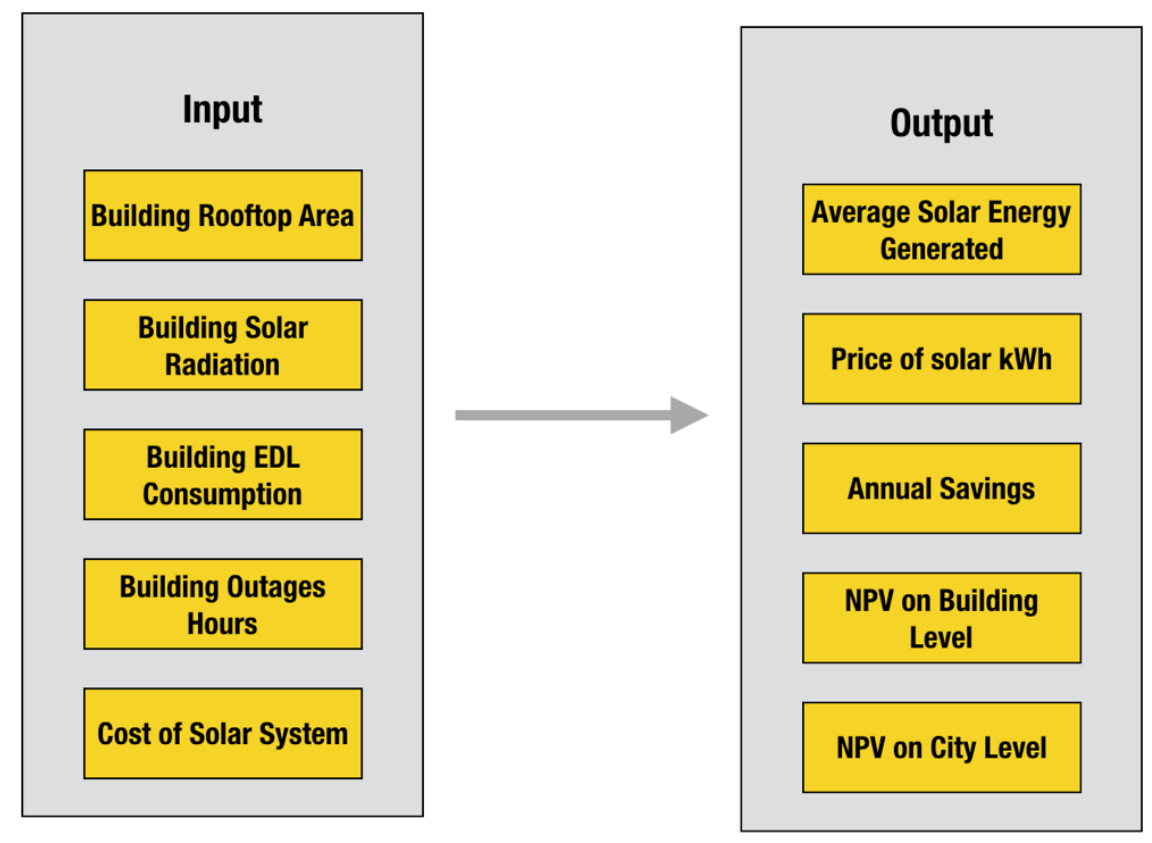

Figure 2: Input and output parameters of the solar PV adoption model

The energy consumption per building is the sum of the consumption of individual apartments (subscribers) based on bimonthly EDL billing and the consumption during the power outages which is typically supplied by diesel generators. The average per hour consumption of diesel generator electricity is assumed to be the same as EDL's regardless of whether the outages happen during the day or night. This assumes no behavioral shift (in reality, diesel generator electricity consumption may vary because it is more expensive than EDL tariffs and there would be possible shifting resulting from the recent metering ordinance for diesel generator supply). EDL's bill component is a step function based on its tiered system (EDL, 2019b).

Therefore, the total annual electricity bill for building $\mathrm{j}, B_{j}^{T O T}$, can be expressed as:

$B_{j}^{T O T}=\sum_{i}^{12} \quad C_{i j} \times T_{e f f}$

Where $C_{i j}$ is the monthly consumption of building $\mathrm{j}$ in month $\mathrm{i}$ and $T_{e f f}$ is the effective tariff of the combination of EDL and generator bills. While $C_{i}$ is half of EDL's bimonthly bill, $T_{e f f}$ is calculated as follows:

$T_{e f f}=\frac{T_{E D L} \times H_{E D L}+T_{G} \times\left(24-H_{E D L}\right)}{24}$ 
Where $H_{E D L}$ is the average daily hours of supply of EDL electricity, $T_{E D L}$ is EDL's tariff, and $T_{G}$ is the generator tariff.

To assess the solar resources available for building $\mathrm{j}$, the calculations are based on the following formula:

$\operatorname{AvailableSpace}\left(S_{j}^{a v}\right)=\beta_{j} \times A_{j}$

Where $S_{j}^{a v}$ is the available space for solar panels in $\mathrm{m} 2, \beta$ is the occupancy factor (in this paper, occupancy refers to the availability of space on the roof, i.e., the higher the occupancy, the higher the space available to install solar PV systems) and A is the rooftop area of a building $\mathrm{j}$. Therefore, the available solar resource for building $\mathrm{j}$ can be expressed as:

$E_{j}^{P V}=\sum_{i}^{12} \quad S_{j}^{a v} \times I_{j}^{i} \times \varepsilon$

Where $E_{j}^{P V}$ is the annual generated solar energy in building $\mathrm{j}$ in $\mathrm{kWh}, I_{j}^{i}$ is the monthly irradiation received by building $\mathrm{j}$ in month $\mathrm{i}$, and $\varepsilon$ is the PV system efficiency. As for the capital cost of the solar PV system in building $\mathrm{j}, K_{j}^{P V}$, it can be estimated using the following formula:

$K_{j}^{P V}=\frac{S_{j}^{a v}}{A_{k W p}} \times k$

Where $A_{k W p}$ is the area required for $1 \mathrm{kWp}$ and $\mathrm{k}$ is the capital cost of the solar PV system in $\$ / \mathrm{kWp}$.

The annual savings that result from installing rooftop solar PV panels, $\Phi_{j}$, can then be estimated using the following equation (it is assumed that the solar energy generated during the day would contribute towards offsetting the EDL and generator bills):

$\Phi_{j}=\sum_{i}^{12} \quad\left(C_{i j}-S_{j}^{a v} \times I_{j}^{i} \times \varepsilon\right) \times T_{e f f}$

On the other hand, the NPV(j) can be calculated as follows:

$N P V(j)=\left(\Phi_{j} \times \omega\right)-K_{j}^{P V}$

Where $\omega$ is the discounting factor over the lifetime of the PV system (20 years), expressed as:

$\omega=\sum_{1}^{n=20} \frac{1}{(1+r)^{n-1}}$

Where $r$ is the discount rate.

It should be noted that outlier buildings were removed from the studied dataset. These were buildings with rooftops below $40 \mathrm{~m} 2$ or buildings with zero electricity consumption. The assumptions used in studying the adoption of rooftop solar PV are listed in Table 1. 
Table 1: Assumptions used in studying the feasibility of rooftop solar PV systems

\begin{tabular}{|l|l|}
\hline Parameter & Value \\
\hline Discount Rate & $10 \%$ \\
\hline Effective tariff & Variable (step function) \\
\hline Capital cost & $1000(\$ / \mathrm{kWp})$ \\
\hline Rooftop occupancy factor & $\begin{array}{l}50 \% \quad(\text { Low })-75 \% \quad \text { (High) (sensitivity } \\
\text { analysis) }\end{array}$ \\
\hline System efficiency & $16.5 \%$ \\
\hline Area required per $1 \mathrm{kWp}$ & $8 \mathrm{~m}^{2}$ \\
\hline System lifetime & 20 years - 30 years (sensitivity analysis) \\
\hline
\end{tabular}

The decision to install rooftop solar PV panels is affected by their financial return (i.e. NPV of investing in the PV system), modeled above. Other factors such as general trust in PV technology, environmental consciousness and social pressure play an important role in these decisions. However, modeling these factors is difficult since they are not typically observable and are hard to quantify. To overcome this, we model the solar PV adoption decisions probabilistically (as opposed to using deterministic models). This way, all unobserved factors would be captured by the error term.

Discrete choice models are conventionally used to express the probability that a person chooses a particular alternative among a set of options as a function of observed variables. The probabilistic nature of these models allows the researcher to accommodate unobserved factors of individual and contextual characteristics in the model. Developed by McFadden (1980), these models have been applied in different fields, from transportation research to public policies, including RES adoption (Borchers et al., 2014; Mundaca and Samahita, 2020; Sardianou et al., 2013). By using a parsimonious discrete choice model, we assume that each building (or household) receives a benefit/utility by deciding to install PV technology. The utility of adopting solar PV by a building $\mathrm{j}$ at time $t$ is:

$U_{j t}=\alpha_{j}+\theta_{j}\left(N P V_{j t}\right)+\varepsilon_{j t}$

Where $\alpha$ is the base utility of adoption regardless of economic benefits (i.e. it captures how much people value using green energy to replace non-RET), $\theta$ is the propensity to the net economic benefits derived from adopting PV (it also can be defined as a function of neighborhood-level demographics), $N P V_{j t}$ is the financial payoff from investment in PV discounted to the present time t. $\varepsilon_{j t}$ is an additive random shock to the utility (i.e. capturing unobserved factors). Following the extant literature (McFadden, 1980) on probabilistic consumer choice models, this random term is assumed to have extreme value distribution. The following logit equation represents the formula for calculating the adoption probability for building $\mathrm{j}$ at time $\mathrm{t}$ : 
$P_{j t}=\frac{\exp \left(\alpha_{j}+\theta_{j}\left(N P V_{j t}\right)\right)}{1+\exp \left(\alpha_{j}+\theta_{j}\left(N P V_{j t}\right)\right)}$

To be able to use the above logit equation to calculate PV adoption probabilities for each building in the dataset, we need to calculate the NPVs and to substitute the values of the two parameters, $\alpha$ and $\theta$. Estimation of these two parameters is a separate task that requires having a representative dataset of the buildings who have adopted solar PV at different times in the past for calibration. Since the buildings in our dataset are yet to install solar PV, we cannot calibrate the two parameters using the current dataset. To overcome this and benefit from the additional insights derived from the adoption probability model, we utilize an auxiliary time series data of the total number of solar panel installations in Lebanon from 2011 to 2018 (LCEC, 2019). Based on the census of buildings in Lebanon, there are roughly 18000 buildings in Beirut (CBDE, 2004). Given that around 10\% of solar PV installations in Lebanon are in Beirut (LCEC, 2019), we compiled the annual time series data of the solar PV adoption proportions for the city of Beirut as our dependent variable. The average annual turnkey price for the above-mentioned period was also compiled (LCEC, 2019). Using these prices, we calculated the average annual NPV for PV installation for the 2200 buildings in our dataset. These values are used as our independent variable. Thus, by assuming homogeneity and no endogeneity for the sake of simplicity, we can invert the natural logarithm of observed annual percentages of solar PV adoption in Beirut to estimate $\alpha$ and $\theta$ using the least square method (Berry et al., 1995). Performing sensitivity analysis, we cover the parameter ranges so that the results become are robust and generalizable.

\section{Results}

\subsection{City-wide rooftop solar PV potential}

The potential of a city-wide deployment model of rooftop solar PV systems is examined, underlined by mapping the solar resources available based on rooftop spaces, the amount of solar insolation received and the financial analysis based on the available data. Fig. 3 shows that 31\% of buildings have a surface area of less than $100 \mathrm{~m} 2,70 \%$ with less than $200 \mathrm{~m} 2$, and 85\% with less than $300 \mathrm{~m} 2$ of surface area. One important parameter in assessing the potential of rooftop solar PV is the occupancy factor. In this study, two cases were considered: a low case with an occupancy factor of $50 \%$ and a high case with $75 \%$. The utilized range of the occupancy factor has been adopted from reports by the World Bank (Ahmad, 2020) and United Nations Development Program (UNDP, 2014). Whilst some buildings would have occupancy factors either below 50\% or higher than $75 \%$, this range can be safely assumed for this assessment to cover most buildings. Assuming that the area required per $1 \mathrm{kWp}$ is $8 \mathrm{~m} 2$, the distribution shown in Fig. 3 can be converted to a solar PV capacity distribution with a minimum and maximum value, depending on the occupancy factor. The average rooftop area based on the studied dataset is $185 \mathrm{~m} 2$, which translates into an average capacity of $12-17 \mathrm{kWp}$, depending on the rooftop occupancy factor.

Fig. 4 shows a projected city-wide distribution of the buildings in the studied dataset in terms of their type (commercial/industrial, residential and mixed) and corresponding solar energy generation capacity. This is done assuming that the ratios of building types and average capacity would remain the same when extrapolating to all buildings in Beirut. The results show that Beirut alone has a potential for distributed rooftop solar PV between 195 and $295 \mathrm{MWp}$, corresponding to occupancy factors of $50 \%$ and $75 \%$, respectively. 
One can extrapolate the above analysis to the rest of Lebanon's buildings, but the results would be somewhat conservative. In rural regions, buildings tend to have larger rooftop areas (compared to urban regions) and therefore higher average theoretical capacity for solar PV.

Table 2 shows that commercial/industrial buildings have the highest average theoretical capacity, between 19 and $28 \mathrm{kWp}$. In fact, in the studied dataset, many of these buildings have a rooftop area of more than $1000 \mathrm{~m}^{2}$, with the maximum surface area found to be approximately $5,900 \mathrm{~m}^{2}$, which would mean the potential installation of approximately $550 \mathrm{kWp}$ at an occupancy factor of $75 \%$ (Najem, 2018).

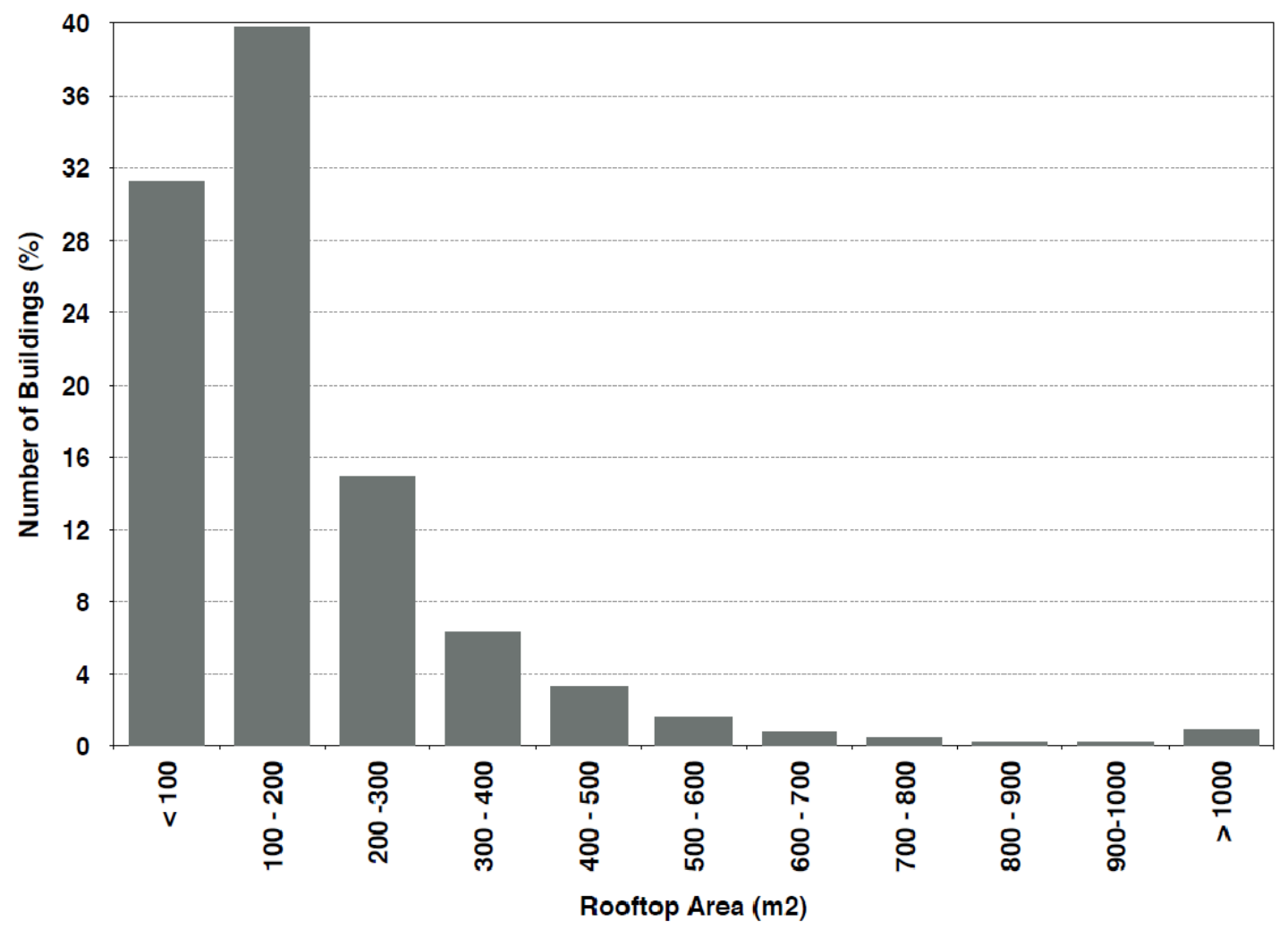

Figure 3: Distribution of rooftop surface areas in a sample of 2200 buildings in Beirut

Table 2: Estimate of Beirut City Solar PV rooftop potential

\begin{tabular}{|l|l|l|l|l|l|}
\hline $\begin{array}{l}\text { Type of } \\
\text { Building }\end{array}$ & $\begin{array}{l}\text { Average Area } \\
\left(\mathbf{m}^{2}\right)\end{array}$ & $\begin{array}{l}\text { Capacity - Low } \\
(\mathbf{k W p})\end{array}$ & $\begin{array}{l}\text { City } \\
\text { Potential - } \\
\text { Low (MW) }\end{array}$ & $\begin{array}{l}\text { Capacity -High } \\
(\mathbf{k W p})\end{array}$ & $\begin{array}{l}\text { City Potential - } \\
\text { High (MWp) }\end{array}$ \\
\hline Commercial & 300 & 18.8 & 19.3 & 28.1 & 29 \\
\hline Residential & 160 & 10 & 95.7 & 15 & 143.6 \\
\hline Mixed & 205 & 12.8 & 82 & 19.2 & 122.9 \\
\hline Total & & & 197 & & 295.5 \\
\hline
\end{tabular}




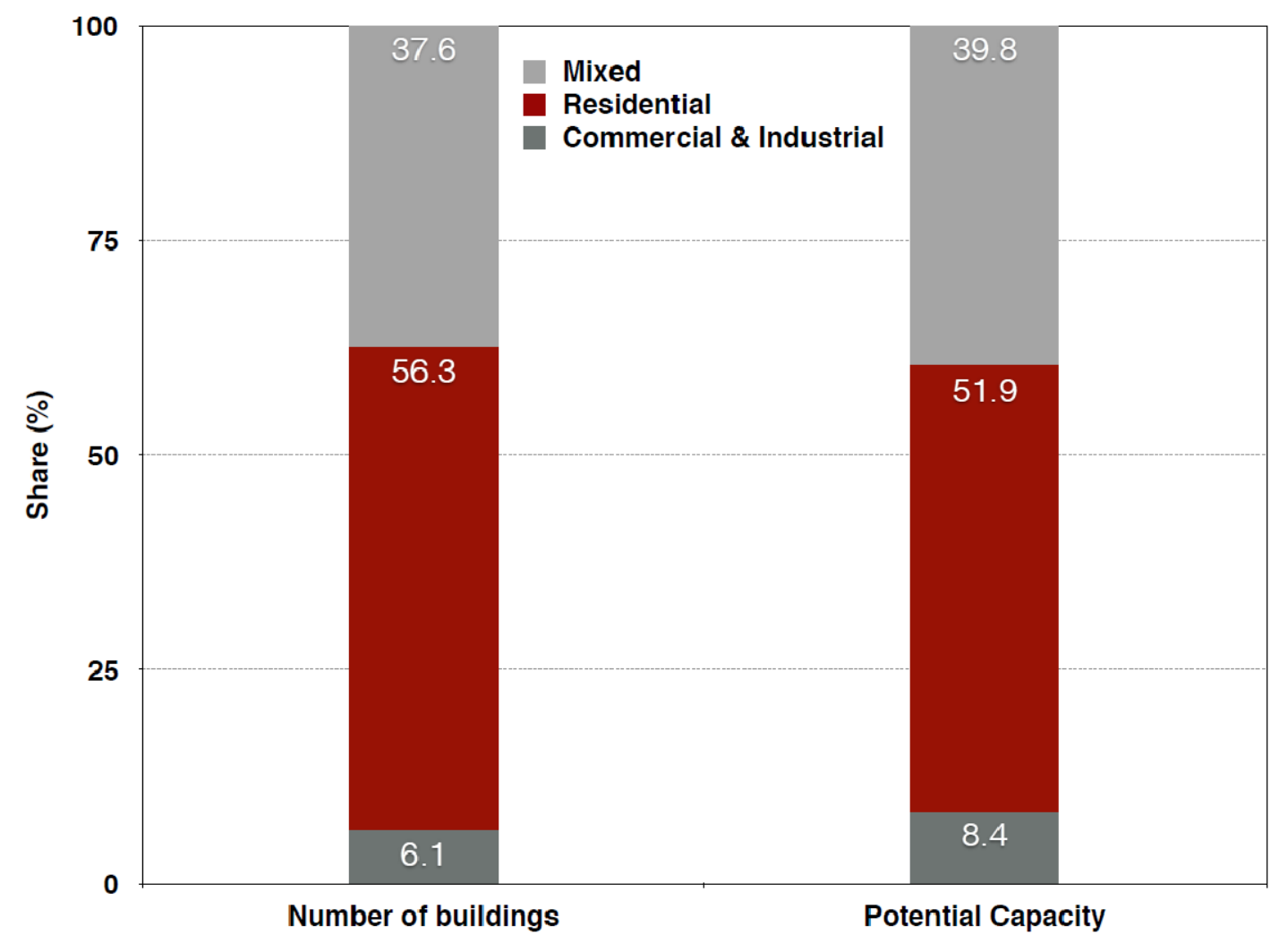

Figure 4: Distribution of commercial/industrial, residential and mixed buildings in the studied dataset by their number and potential solar PV capacity

\subsection{Building level analysis}

Based on NPV calculations for the potential installed PV (with assumptions as shown in Table 1), we assessed the number of buildings for which financial investment in solar PV is positive. The question, therefore, becomes: if the economic aspect is the only factor considered, how many buildings from the studied dataset would install solar PV and which buildings would benefit more from such an investment?

Table 3: NPV assessment of rooftop solar PV systems in Beirut

\begin{tabular}{|l|l|l|l|}
\hline & $\begin{array}{l}\text { Percentage of Positive } \\
\text { NPV }\end{array}$ & $\begin{array}{l}\text { Total NPV } \\
\text { (USD) }\end{array}$ & $\begin{array}{l}\text { City Average NPV } \\
\text { (USD) }\end{array}$ \\
\hline $\begin{array}{l}\text { Baseline Scenario (50\% } \\
\text { Rooftop Space Availability) }\end{array}$ & 73 & 18166268 & 8272 \\
\hline $\begin{array}{l}\text { Increasing Rooftop Space to } \\
75 \%\end{array}$ & 69 & 23900329 & 10883 \\
\hline
\end{tabular}

The results (Table 3 ) show that in the baseline scenario, $73 \%$ of the buildings would get positive returns from rooftop PV installation, with each building receiving 8272 USD on average. In contrast, if the usable rooftop area for PV panels increases from $50 \%$ to $75 \%$ (by using better technology or better space design), the percentage of buildings receiving positive returns on 
investment slightly decreases to $69 \%$. This looks counterintuitive at first, but can be explained by examining the changes in the total and average NPV figures. Even though on the one hand, the increase in usable space can lead to an increase in solar panel size and consequently increased solar energy output, on the other hand, it also leads to an increase in the cost of PV installation. In this case, some buildings with high electricity consumption would benefit from an increase in rooftop area, while buildings with low consumption would receive negative returns on investment since the initial cost of solar panels outweighs their economic benefits.

The lifespan of solar PV panels is variable depending on many factors such as its manufacturer, technology, and operating conditions. It is conventionally accepted in the market that the typical guaranteed lifespan of solar panels range between 20 to 30 years (Lazard, 2018). A sensitivity analysis was used to test the impact of the PV lifespan on our results. The analysis does not show significant changes in the percentages of positive NPV when we increase the lifespan from 20 to 30 years. This is because investment returns from solar PV after year 20 are heavily discounted (to be converted to the present values), and thus do not change the NPV significantly. Conservatively and to minimize issues of performance degradation (Kumar et al., 2019), we use 20 years of lifespan as the baseline value. The results of the sensitivity analysis are shown in Table A-1 in the appendix. It should be noted that the model only accounts for self-consumption; i.e. no power is exported to EDL's grid. However, it shows the importance of the effective implementation of a policy instrument such as net-metering to allow the export of excess electricity to the grid. Since power outages are frequent in Lebanon, effective and financially viable net-metering remains a challenge. In this context, policy recommendations involving smart rationing of EDL's intermittent power supply could mitigate some of the risks (Krayem et al., 2019).

Negative returns on investment can also be avoided if householders consult solar energy engineers on proper sizing of rooftop panels for buildings. Our proposed model would allow energy policy makers to indicate the right size of the rooftop solar PV panels for each building based on its characteristics (e.g. area, height, neighborhood, solar irradiation, number of residents, and energy consumption). To showcase this ability in our model, we distinguish between buildings based on their NPV from PV investment using a simple dichotomy of positive and negative NPV and building characteristics. Table 4 below highlights these differences using mean values.

Table 4: Differences between positive and negative NPV buildings

\begin{tabular}{|l|l|l|l|l|l|}
\hline Group & Percentage & $\begin{array}{l}\text { Average } \\
\text { Building } \\
\left.\text { Area } \mathbf{( m}^{\mathbf{2}}\right)\end{array}$ & $\begin{array}{l}\text { Average Annual } \\
\text { Electricity } \\
\text { Consumption (kWh) }\end{array}$ & $\begin{array}{l}\text { Average Annual } \\
\text { Generator Bill } \\
\text { (USD) }\end{array}$ & $\begin{array}{l}\text { Residential } \\
\text { Buildings } \\
\text { Percentage }\end{array}$ \\
\hline $\begin{array}{l}\text { Positive } \\
\text { NPV }\end{array}$ & 74 & 221 & 13130 & 9625 & 52 \\
\hline $\begin{array}{l}\text { Negative } \\
\text { NPV }\end{array}$ & 26 & 186 & 3778 & 2606 & 68 \\
\hline
\end{tabular}

The results show significant differences across positive and negative NPV with larger buildings that have more residents and whose annual electricity consumption (and thus annual generator bills) is higher benefiting more from solar PV investment, and commercial buildings benefitting the most. Looking solely at the NPV, the majority of buildings would receive returns on investment, with some benefiting more than others, but as mentioned earlier, other non-economic 
factors could play a role. To take these into account, we use a probabilistic choice model to calculate the adoption probability of the buildings in our dataset, using the two parameters estimated, $\alpha$ and $\theta$.

Table 5 below shows the original parameters and their variation based on different scenarios used in the sensitivity analysis. $\alpha$ is the value of solar PV as a green energy source regardless of its economic value and $\beta$ is the propensity of the return on investment for solar PV. To include different contingencies on these parameters into account, three scenarios were considered in addition to the baseline case, which is estimated based on the average NPV in our dataset. In case 2, we consider the situation where the NPV level is high across the buildings (i.e. average plus one standard deviation). In case 3, the NPV is considered to be low (i.e. average minus one standard deviation). In case 4, a hypothetical scenario is considered in which the parameters calibrated in a German market were used as a benchmark (Eslami Dizeje, 2015).

Table 5: Parameters of the Solar Panels Adoption Choice Model

\begin{tabular}{|l|l|l|l|c|c|}
\hline Parameter & Interpretation & $\begin{array}{l}\text { Case 1: } \\
\text { Baseline } \\
\text { Values }\end{array}$ & $\begin{array}{l}\text { Case 2: } \\
\text { High NPV }\end{array}$ & $\begin{array}{l}\text { Case 3: } \\
\text { Low NPV }\end{array}$ & $\begin{array}{l}\text { Case 4: } \\
\text { German } \\
\text { Market }\end{array}$ \\
\hline $\boldsymbol{\alpha}$ & $\begin{array}{l}\text { Importance of solar energy (i.e. } \\
\text { going green) irrespective of its } \\
\text { financial return }\end{array}$ & -6.16 & -8.43 & -5.81 & -2.63 \\
\hline $\boldsymbol{\theta}$ & $\begin{array}{l}\text { Importance of the financial return } \\
\text { of investing in solar panels }\end{array}$ & 0.045 & 0.114 & 0.024 & 0.092 \\
\hline \multicolumn{2}{|l|}{ Residential Buildings Adoption Percentage } & 0.49 & 0.71 & 0.39 & 15.2 \\
\hline \multicolumn{2}{l}{ Commercial Buildings Adoption Percentage } & 1.23 & 3.89 & 0.56 & 26.3 \\
\hline
\end{tabular}

As shown in Table 5, under the baseline scenario (i.e. average NPV level), $0.49 \%$ of residential buildings and $1.23 \%$ of commercial buildings would install rooftop PV. Contrasting the results to those of Table 4, the percentage of adoption is much less. Since this approach incorporates factors other than financial return on investment (i.e. unobserved factors such as attitude towards renewable energy), the results look more realistic. It should be noted that the observed adoption percentage in Beirut is below $2 \%$ based on the aggregate data (LCEC, 2019). Moreover, in line with the results given in Table 4, the percentage of adoption among commercial buildings is significantly higher. Case 2 represents a situation in which people do not value the environmental aspects of solar energy much but attach a higher value to its return on investment. In this case, the percentage of adoption increases both for residential and commercial buildings. Case 3 represents a situation where people do not value the environmental aspects of solar PV and at the same time are not sensitive to its financial return, which results in the lowest adoption proportion among the scenarios considered. Case 4 - a hypothetical scenario based on the behavior of the people in Germany - results in high adoption rate. Comparatively, it shows that the people in Germany attach much higher importance to the environmental aspects of solar PV while they are sensitive to its financial returns. As such, it is not surprise to see that the adoption percentages would be much higher in this case. For cross country comparison studies in terms of RES and sustainability initiatives, the index developed by Yale University (EPI, 2019) is recommended. To summarize, 
if people have a better attitude towards RES, they would adopt solar panels at a higher rate. On the other hand, the financial aspects of investing in PV alone can, to some extent, compensate for people's low interest in green energy sources. However, to achieve deeper levels of RES adoption, efforts and policies need to go beyond promoting financial feasibility to driving cultural and societal norms that value green energy solutions.

\subsection{Importance of building level analysis}

In this paper, we have utilized a spatial rich dataset of solar irradiation augmented by electricity bills at the building level. This has enabled us to estimate the solar potential for each building and to model the solar PV adoption decision at the building level. To highlight the merits of such an approach, a benchmarking analysis is used. To do so, we re-estimated our model under conditions where solar irradiation is the same across different buildings, they all consume the same amount of electricity, or they all have the same rooftop area. In other words, if we ignore the fact that different buildings in the metropolitan area have different heights, areas, and electricity consumption habits, the model outcome would be different.

Table 6: Benchmarking on the importance of building level analysis

\begin{tabular}{|l|l|l|l|c|}
\hline & $\begin{array}{l}\text { Baseline } \\
\text { Scenario } \\
\text { (Building level } \\
\text { analysis) }\end{array}$ & $\begin{array}{l}\text { Scenario 1: } \\
\text { Common solar } \\
\text { irradiation across } \\
\text { the buildings }\end{array}$ & $\begin{array}{l}\text { Scenario 2: } \\
\text { Common electricity } \\
\text { consumption across } \\
\text { the buildings }\end{array}$ & $\begin{array}{l}\text { Scenario 3: } \\
\text { Common } \\
\text { rooftop area } \\
\text { across the } \\
\text { buildings }\end{array}$ \\
\hline $\begin{array}{l}\text { Residential Buildings } \\
\text { Adoption Percentage }\end{array}$ & 0.49 & 3.08 & 0.39 & 0.3 \\
\hline $\begin{array}{l}\text { Commercial Buildings } \\
\text { Adoption Percentage }\end{array}$ & 1.23 & 6.51 & 1.1 & 0.37 \\
\hline
\end{tabular}

The benchmarking results in Table 6 show clearly that if we ignore the fact that the buildings in the metropolitan area are different, our estimation of solar PV potential would be biased. This bias is most severe under Scenario 1 where we assumed that all buildings receive the same amount of solar irradiation. In this case, the potential for solar PV is overestimated by almost $400 \%$. While this bias is lessened under the second and third scenarios, it is important to note that if we conduct the analysis at an aggregate city level, our results could be significantly biased (i.e. the combination of the three bias sources shown in the above table) if the buildings in the study context are heterogeneous. Therefore, the proposed framework allows policy makers to design appropriate incentives for different segments of customers, residential and commercial, to achieve desirable targets given their knowledge of the country and available resources. In the discussion section, we will elaborate more on the impact of different incentive policy instruments on rooftop PV adoption.

\section{Discussion}

\subsection{Impact of various policy instruments and market forces}

Renewable energy options are far from being the mainstream choice among customers (Heng et al., 2020; Higueras-Castillo et al., 2019). We posit that the role of policy makers and appropriate 
incentive policy instruments are crucial in boosting the diffusion of technologies such as rooftop $\mathrm{PV}$. A viable question is the impact of various policy instruments on the adoption decision-making of different customer groups in different markets. For this, we investigate the role of different green incentive instruments on the widespread adoption of PV in Lebanon. The modeling framework proposed earlier, in addition to the detailed data on the characteristics of buildings in Beirut with exact solar irradiation received, allow us to perform such a policy analysis. Table 7 below lists the various policy instruments that can be adopted in Lebanon based on their impact on the diffusion of rooftop PV and their corresponding costs/downsides.

Table 7: Impact of selected policy instruments and market changes

\begin{tabular}{|l|l|l|l|l|l|}
\hline Policy & $\begin{array}{l}\text { Percentage of } \\
\text { Positive NPV }\end{array}$ & $\begin{array}{l}\text { Total NPV (USD } \\
\text { Million) }\end{array}$ & $\begin{array}{l}\text { City Average } \\
\text { NPV (USD) }\end{array}$ & $\begin{array}{l}\text { Residential } \\
\text { Adoption } \\
\text { Percentage }\end{array}$ & $\begin{array}{l}\text { Commercial } \\
\text { Adoption } \\
\text { Percentage }\end{array}$ \\
\hline $\begin{array}{l}\text { Baseline } \\
\text { Scenario }\end{array}$ & 73 & 18.17 & 8272 & 0.49 & 1.23 \\
\hline $\begin{array}{l}\text { Doubling EDL } \\
\text { Tariffs }\end{array}$ & $84(+15 \%)$ & $52.0(+180 \%)$ & 23700 & 1.84 & 7.56 \\
\hline $\begin{array}{l}\text { Solar system } \\
\text { costs reduced } \\
\text { by half }\end{array}$ & $87(+19 \%)$ & $32.7(+80 \%)$ & 14898 & 0.77 & 2.61 \\
\hline $\begin{array}{l}\text { Subsidized } \\
\text { interest rate } \\
\text { (from } 10 \% \\
\text { down to } 1 \%)\end{array}$ & $82(+12 \%)$ & $26.5(+45 \%)$ & 12075 & 0.64 & 1.94 \\
\hline
\end{tabular}

Compared to the baseline scenario, the three following scenarios are considered: (1) removal of EDL subsidies, which is equivalent to doubling the current tariff; (2) reducing the system costs of solar PV by $50 \%$ to reflect future cost levels as the market and technology mature; and (3) subsidizing the interest rate on loans given to individuals and businesses who are interested in deploying solar PV solutions from the current market rate of $10 \%$ to a subsidized rate of $1 \%$. All three scenarios have yielded a substantial increase in adoption percentages from the baseline values of $0.49 \%$ and $1.23 \%$ in the residential and commercial buildings, respectively. When doubling EDL's tariff across all tiers, the adoption rate in all building sectors almost quadruples. This is a direct result of the additional importance given to cost savings induced by PV systems compared to current tariff levels. From EDL's perspective, and assuming EDL's cost recovery remains negative, the increased adoption would lower the utility's losses. Consequently, this shows that tariff adjustment is not only a necessary component of reform to achieve cost recovery by EDL, it is an imperative step to remove market distortions that impede a higher growth of renewable energy systems in general. The challenge, however, is that tariff reforms is politically costly and deeply connected to Lebanon's political economy.

The second scenario is when the total system costs of rooftop solar PV are reduced by $50 \%$. Since $\mathrm{PV}$ technology is capital intensive, lowering the capital cost increases the percentage of positive NPV of a deployed system the most ( $+19 \%$ compared to the baseline scenario), though it offers 
the least increase in adoption percentages. This is because the upfront capital cost of PV becomes less important and the rooftop systems considered are of small capacity. In the third scenario, where the interest rates on loans are subsidized, the effect is very similar to the first intervention, however, in this case the government (or in the case of Lebanon, the Central Bank) carries the burden of this subsidy. This subsidy is justified to start up the development of the solar industry in the country but it is by no means an economically efficient way to be pursued in the long term. As expected, the impact of lowering the discount rate is substantial. Consequently, attempts to de-risk the renewable energy sector (UNDP, 2018) should be given priority by the Lebanese government as it would further propel the market with a lower fiscal burden on the treasury.

\subsection{Distributed power generation under economic fragility}

As mentioned earlier, large parts of Lebanon's economic woes resulted from energy sector failings on economic, policy and governance levels. The current economic crisis facing Lebanon (Diwan, 2020) underlines the fact that the status quo can no longer be maintained and a shift towards more economic and sustainable models is imminent. Since the current crisis has a fiscal dimension related to foreign currency shortages (mainly US dollar) in the Central Bank and commercial banks, the import of petroleum fuel to power thermal generation, through EDL and informal diesel generators, is putting immense pressure on Lebanon's dwindling foreign currency reserves.

Prior to the civil unrest resulting from the economic crisis beginning in October 2019, the government planned to increase the tariff in an attempt to phase out subsidies. However, this now seems to be unlikely in the current political environment. Alternatively, EDL's budget reduction will be reflected in the company lowering its supply hours. Assuming that the average oil price remains the same as 2019 with no substantial behavioral shift in consumption patterns, the cash transfer reduction will result in a $20 \%$ loss of EDL supply $(\sim 3 \mathrm{TWh})$. The increased deficit will be met by private diesel generators, which are more expensive than EDL electricity (average EDL tariff is around 9 cents $/ \mathrm{kWh}$ while the diesel generators' is around 30 cents $/ \mathrm{kWh}$ ), increasing energy costs for households. If the devaluation of the Lebanese Pound and the diminishing purchasing power are taken into account, the increased energy cost will have a deeper impact on income allocation, especially for low-income households.

Although tariff increase in this case is in line with the "doubling tariff" scenario studied above, it would occur in a strained economic environment. Although this boosts the economic case for solar $\mathrm{PV}$, the ability of residential and commercial sectors to invest in such capital-intensive systems will be greatly reduced. So far, anecdotal evidence shows a substantial slowdown in Lebanon's RES sector in 2019 and this is expected to continue into 2020 (private communication with PV companies in Lebanon). In hindsight, the economic crisis in Lebanon adds to the compelling case for distributed RES as an option that provides energy security and resilience, as well as economic and environmental benefits. One of the lessons learned from the current situation is that the Lebanese government should fast-track and implement the required legal framework to facilitate and incentivize distributed power generation from RES, bearing in mind the value-added for citizens and businesses alike beyond their immediate economic benefits.

\subsection{Societal incentives for adopting rooftop PVS}

Any assessment of the potential role of solar PV should take into account societal and cultural factors that affect people's perception and adoption of energy technologies, beyond financial and economic models (Sovacool, 2014). Understanding the social and cultural factors in the local context is crucial for a better appreciation of the dynamics affecting energy transformation, policy 
and practice, not least since they affect adoption rates of new energy innovations (c.f. Heng et al., (2020) in the US and Higueras-Castillo et al. (2019) in Europe).

Several studies have looked at the social impacts of electricity in Lebanon, showing how these services are crucial in shaping the relationship with the state, where the sector's failures resulted in civil mobilizations (Verdeil, 2016) and raised notions of mistrust and resistance towards particular policies perceived as partisan and sectarian, factors that remain strong in Lebanese society (Verdeil, 2018). Other studies have explored the impact of power outages on people's everyday lives, showing the impact of private generators services on households (Abi Ghanem, 2018). More recently, research has focused on specific regions in Lebanon, including the rise of new market actors seeking to replace the current model of electricity supply provision (a combination of EDL and private generators) in two cities in Lebanon with a local electricity distribution network, highlighting considerable socio-political impacts on the regional and national levels (Verdeil, 2019). These works indicate that at the core of electricity provision, regardless of scale or geography, several social and political dynamics come into play to influence the way different policy and technological options are conceived, not least the notion of co-managing electricity supply using technologies like rooftop PVs.

The adoption of solar PV is also closely linked to socio-cultural factors. Elmustapha et al. (2018) examined household level variables in relation to PV adoption in Lebanon and found family income lifecycles (patterns of periodic income variability) and socio-demographic attributes (income level, education) to be the main drivers for investments. Non-economic aspects included notions of comfort and the compatibility of the solar systems (their function and technical requirements) with people's lifestyle, as well as perceptions of the technology. Importantly, social ties and networks between individual households were important contributors to the propensity for adoption due to the importance of social interactions and the PVs visibility. From this brief overview, we can highlight three discussion points regarding the potential for solar PV adoption in Beirut. Firstly, the promotion of the technology through demonstration projects that enhance the visibility of PV panels can have positive impacts in relation to raising awareness of the technology. To clarify, perspectives from sustainable transitions literature (Geels, 2010) highlight the importance of nurturing technologies in early adoption contexts (Smith and Raven, 2012) and as such, initiatives that promote rooftop PV systems through various policy instruments should be prioritized as an effective tool to drive wider adoption.

The second point pertains to unequal access to good quality energy services in Lebanon combined with the still limited penetration of RETs. Accordingly, a socio-spatial perspective such as the model presented here can enable a holistic understanding of PV adoption that moves away from distinct household-level attributes to wider city-level analysis. This ensures the effectiveness of policies for promoting PVs is not limited to particular sectors (e.g. commercial or residential). Instead, the role of social networks (Elmustapha et al., 2018) and the important role that social learning plays, can be better considered when utilizing a spatial approach. Finally, we point out the socio-spatial aspects of electricity provision in Lebanon, specifically the socio-political dynamics that render electricity services and technologies as sites of contestation. The political struggles faced by consecutive governments in Lebanon and the lack of a unified vision of where and how RES options can play a role, indicate the size of the challenge that needs to be addressed. Importantly, a socially and culturally aware approach that seeks to engage with multiple actors that affect energy-related decision making at household and broader scales is needed. As highlighted by Verdeil (2019), resistance to various electricity infrastructure initiatives and the 
undue influence that private diesel generator providers can have on electricity provision suggest that policies to promote PVs on rooftops should carefully consider these stakeholders insofar as neighborhoods and urban areas are concerned. Therefore, policymakers should be opening up the process to engage with all relevant actors in a manner that responds to the multiple concerns and economic interests arising from PV adoption.

\section{Conclusion and future work}

Based on current market and technology conditions, distributed rooftop solar PV systems are already cost competitive for the majority of buildings in Beirut. Our results show that $73 \%$ of the buildings in the studied dataset would obtain positive returns from rooftop PV panels. On average, each building in Beirut would receive an NPV of approximately US\$ 8300. Compared to the baseline case, if the rooftop area usable for solar PV panels increases from $50 \%$ to $75 \%$, the proportion of buildings which would receive positive NPV slightly decreases to $69 \%$. This counter intuitive result reflects the limitation of the economic case for the "self-consumption" model when savings do not offset investment costs. As such, the ability to export electricity to the grid should be prioritized for the diffusion of rooftop PV systems to be expanded. Our analysis yields an estimate of rooftop solar PV potential for the city of Beirut between 195 and 295 MWp, corresponding to space availability factors of $50 \%$ and $75 \%$, respectively. On average, commercial and industrial buildings have the highest average theoretical capacity, between 19 and $28 \mathrm{kWp}$, compared to $15 \mathrm{kWp}$ for residential buildings.

Based on the probabilistic choice model, the numbers are markedly low. Under the baseline scenario, cultural factors not favorable towards adopting rooftop PV systems will lead to diffusion of $0.49 \%$ among residential and $1.23 \%$ among commercial buildings. This shows that in Lebanon, a more positive attitude towards RETs would lead to higher rates of PV adoption, while economic aspects of investing in PV can compensate people's low interest in RETs. Using a benchmarking study, we show that not accounting for differences between the buildings in a metropolitan area could bias the estimates of PV's potential.

In relation to future research, there is a need to expand on the impact of various policy instruments highlighted in this paper. While these policies can be effective, the cost of their implementation can vary under different conditions and contexts. Furthermore, although this paper studied people's acceptance of solar PV as a function of societal factors, the underlying model can be enhanced by utilizing building-level longitudinal data for calibrating the parameters of the probabilistic choice model, which has been challenging due to the current lack of available data. The data needed to refine the model in the future would consist of the chronological and spatial evolution of solar rooftop deployment in Beirut, detailed costs of PVs and in-depth sociopolitical insights on electricity provision. Beyond Lebanon, taking into consideration the proposed modeling framework, we have shown how this study can be replicated in other transition economies in the region.

Author contribution Hossein Eslami: Conceptualization; Methodology; Formal analysis; Writing. Sara Najem: Data curation; Methodology. Dana Abi Ghanem: Formal analysis, Writing/Editing. Ali Ahmad: Conceptualization; Formal analysis; Writing.

Declaration of competing interest The authors declare that they have no known competing financial interests or personal relationships that could have appeared to influence the work reported in this paper. 


\section{References}

Abi Ghanem, D., 2018. Energy, the city and everyday life: Living with power outages in postwar Lebanon. Energy Res. Soc. Sci. 36, 36-43. https://doi.org/10.1016/j.erss.2017.11.012

Abi Ghanem, D. and Haggett, C. 2013. Shaping people's engagement with microgeneration technology: the case of solar photovoltaics in UK homes. In Devine-Wright, P. (ed.) Renewable Energy and the Public: from NIMBY to Participation. London: Earthscan, 149-166.

Ahmad, A., 2020. Distributed Power Generation for Lebanon: Market Assessment and Policy Pathways. World Bank. https://openknowledge.worldbank.org/handle/10986/33788?locale-attribute=es

Ahmad, A., 2019. If not now, when? The urgent need for a national dialogue on energy in Lebanon. Issam Fares Institute Op-Ed. Issam Fares Institute for Public Policy and International Affairs, American University of Beirut.

http://aub.benchurl.com/c/v? $=$ DCD5CC \&c $=33 \mathrm{CE} 3 \& \mathrm{t}=0 \& \mathrm{l}=11 \mathrm{FAEA0E} \&$ email $=$ ioKIrISfjc $6 \mathrm{dF}$ ZzxJaqp8Q\%3D\%3D

Al-Irsyad, M.I., Halog, A., Nepal, R., 2019. Estimating the impacts of financing support policies towards photovoltaic market in Indonesia: A social-energy-economy-environment model simulation. J. Environ. Manag. 230, 464-473. https://doi.org/10.1016/j.jenvman.2018.09.069

Amine, J., Rizk, S., 2018. 2017 Solar PV Status Report for Lebanon. United Nations Development Programme.

https://www.undp.org/content/dam/lebanon/docs/EnergyandEnvironment/2017Solar0PVStatusR eportforLebanon.pdf

Berjawi, A. H., Najem, S., Faour, G., Abdallah, C., Ahmad, A., 2017. Assessing Solar PV's Potential in Lebanon. Issam Fares Institute for Public Policy and International Affairs, American University of Beirut. http://www.aub.edu.lb/ifi/Documents/publications/working_papers/20162017/20170808_solar_pvs.pdf

Berry, S., Levinsohn, J., Pakes. A., 1995. Automobile prices in market equilibrium. Econometrica 60 (4), 841-890.

Borchers, A. M., Xiarchos, I., Beckman, J., 2014. Determinants of wind and solar energy system adoption by U.S. farms: A multilevel modeling approach. Energy Policy 69, 106-115.

[dataset] CBDE, 2004. The Census of Buildings, Dwellings and Establishments (CBDE), Central Administration of Statistics, Lebanon. http://www.cas.gov.lb/images/Excel/CBDE-2004.xls 
Dasari, H, P., Desamsetti, S., Langodan, S., Attada, R., Kunchala, R., Viswanadhapalli, Y., Knio, O., Hoteit, I., 2019. High-resolution assessment of solar energy resources over the Arabian Peninsula. Appl. Energy 248, 354-371.

Diwan, I., 2020. Lebanon's Perfect Storm. Project Syndicate. https://www.projectsyndicate.org/commentary/lebanon-political-economic-crises-protests-by-ishac-diwan-2020-01 (accessed 27 February 2020)

Dong, C.G. 2012. Feed-in tariff vs. renewable portfolio standard: an empirical test of their relative effectiveness in promoting wind capacity development, Energ. Policy. 42, 476-485. https://doi.org/10.1016/j.enpol.2011.12.014

[dataset] EDL, 2019a. Daily supply. Electricity of Lebanon. http://www.edl.gov.lb/feeding.php

[dataset] EDL, 2019b. Electricity tariff. Electricity of Lebanon.

http://www.edl.gov.lb/page.php?pid=39

Elmustapha, H., Hoppe, T., Bressers, H. 2018. Understanding Stakeholders' Views and the Influence of the Socio-Cultural Dimension on the Adoption of Solar Energy Technology in Lebanon. Sustain. 10(2), 1-17. https://doi.org/10.3390/su10020364

Enongene, K. E., Abanda, F.H., Otene, I.J.J., Obi, S.I., Okafor, C., 2019. The potential of solar photovoltaic systems for residential homes in Lagos city of Nigeria. J. Environ. Manag. 244, 247-256. https://doi.org/10.1016/j.jenvman.2019.04.039

[dataset] EPI, 2019. EPI Results 2018. Environmental Performance Index. Yale University. https://epi.envirocenter.yale.edu/epi-topline

Eslami Dizeje, H., 2015. Structural model of renewable energy diffusion: The case of solar photovoltaic panels. (Unpublished doctoral dissertation). National University of Singapore, Singapore.

Faiers, A., Neame, C., 2006. Consumer attitudes toward domestic solar power systems. Energ. Policy 34 , 1797-1806. https://doi.org/10.1016/j.enpol.2005.01.001

Fikru, M., 2019. Estimated electricity bill savings for residential solar photovoltaic system owners: Are they accurate enough? Appl. Energy 253, 113501.

https://doi.org/10.1016/j.apenergy.2019.113501 
Geels, F. W., 2010. Ontologies, socio-technical transitions (to sustainability), and the multi-level perspective. Res. Policy 39(4), 495-510. https://doi.org/10.1016/j.respol.2010.01.022

Ghasemi, G., Noorollahi, Y., Alavi, H., Marzband, M., Shahbazi, M., 2019. Theoretical and technical potential evaluation of solar power generation in Iran. Renew. Energy 138, 1250-1261. https://doi.org/10.1016/j.renene.2019.02.068

Heng, Y., Lu, C., Yu, L., Gao, Z., 2020. The heterogeneous preferences for solar energy policies among US households. Energ Policy 137, 111187. https://doi.org/10.1016/j.enpol.2019.111187

Higueras-Castillo, E., Muñoz-Leiva, F., Liébana-Cabanillas, F., 2019. An examination of attributes and barriers to adopt biomass and solar technology. A cross-cultural approach. $J$. Environ. Manag. 236, 639-648. https://doi.org/10.1016/j.jenvman.2019.02.022

Jung, J., Tyner, W.E., 2014. Economic and policy analysis for solar PV systems in Indiana. Energ Policy 74, 123-133. https://doi.org/10.1016/j.enpol.2014.08.027

Karjalainen, S., Ahvenniemi, H., 2019. Pleasure is the profit - The adoption of solar PV systems by households in Finland. Renew. Energy 133, 44-52.

https://doi.org/10.1016/j.renene.2018.10.011

Kaya, O., Klepacka, A., Florkowski, W., 2019. Achieving renewable energy, climate, and air quality policy goals: Rural residential investment in solar panel. J. Environ. Manag. 248, 109309. https://doi.org/10.1016/j.jenvman.2019.109309

Khoury, J., Mbayed, R., Salloum, G., Monmasson, J., Guerrero, J., 2016. Review on the integration of photovoltaic renewable energy in developing countries - Special attention to the Lebanese case. Renew. Sustain. Energy Rev. 57, 562-575.

https://doi.org/10.1016/j.rser.2015.12.062

Kim, J.E. 2020. Regulation trumps economics? Examining renewable energy policy, diffusion and investment in 80 developing countries. Energy Res. Soc. Sci. 70, 101613.

https://doi.org/10.1016/j.erss.2020.101613

Krayem, A., Al Bitar, A., Ahmad, A., Faour, G., Gastellu-Etchegorry, J. P., Lakkis, I., Najem, S., 2019. Urban energy modeling and calibration of a coastal Mediterranean city: The case of Beirut. Energy Build. 199, 223-234. https://doi.org/10.1016/j.enbuild.2019.06.050

Kumar, N. M., Gupta, R. P., Mathew, M., Jayakumar, A., Singh, N. K., 2019. Performance, energy loss, and degradation prediction of roof-integrated crystalline solar PV system installed in Northern India. Case Stud. Ther. Eng. 13, 100409.

Lazard, 2018. Lazard's Levelized Cost of Energy Analysis - Version 12. https://www.lazard.com/media/450784/lazards-levelized-cost-of-energy-version-120-vfinal.pdf (accessed 2 October 2019) 
LCEC, 2019. 2018 Solar PV Status Report for Lebanon. The Lebanese Center for Energy Conservation, Lebanon.

http://lcec.org.lb/en/LCEC/DownloadCenter/Others\#page=4 (accessed 15 September 2020)

Li, X., Lin, A., Young, C., Dai, Y., Wang, C., 2019. Energetic and economic evaluation of hybrid solar energy systems in a residential net-zero energy building. Appl. Energy 254, 113709. https://doi.org/10.1016/j.apenergy.2019.113709

McFadden, D., 1980. Econometric Models for Probabilistic Choice Among Products. J. Bus. 53(3), s13-s29. https://jstor.org/stable/2352205

MEW, 2019. Updated Policy Paper for the Electricity Sector. https://www.energyandwater.gov.lb/mediafiles/articles/doc-100515-2019_05_21_04_27_25.pdf

Mohandes, N., Sanfilippo, A., Al Fakhri, M., 2019. Modeling residential adoption of solar energy in the Arabian Gulf Region. Renew. Energy 131, 381-389.

https://doi.org/10.1016/j.renene.2018.07.048

Mundaca, L., Samahita, M., 2020. What drives home solar PV uptake? Subsidies, peer effects and visibility in Sweden. Energy Res. Soc. Sci. 60, 101319.

Najem, S., 2018. The Beirut Solar Map. In 2018 4th International Conference on Renewable Energies for Developing Countries (REDEC) (pp. 1-4). IEEE.

Najjar, M.B., Ghoulam, E., Fares, H., 2012. Mini Renewable Hybrid Distributed Power Plants for Lebanon. Energy Proced. 18, 612-621. https://doi.org/10.1016/j.egypro.2012.05.074

Nwokocha, C., Okoro, U., Usoh, C., 2018. Photovoltaics in Nigeria - Awareness, attitude and expected benefit based on a qualitative survey across regions. Renew. Energy 116, Part A, 176182. https://doi.org/10.1016/j.renene.2017.09.070

Oh, M., Park, H., 2018. A new algorithm using a pyramid dataset for calculating shadowing in solar potential mapping. Renew. Energy 126, 465-474.

https://doi.org/10.1016/j.renene.2018.03.068

O'Shaughnessy, E., Cutler, D., Ardani, K., Margolis, R., 2018. Solar plus: A review of the end user economics of solar PV integration with storage and load control in residential buildings. Appl. Energy 228, 2165-2175. https://doi.org/10.1016/j.apenergy.2018.07.048.

Pacudan, R., 2018. Feed-in tariff vs incentivized self-consumption: Options for residential solar PV policy in Brunei Darussalam. Renew. Energy 122, 362-374.

https://doi.org/10.1016/j.renene.2018.01.102 
Ransan-Cooper, H., Lovell, H., Watson, P., Harwood, A., Hann, V. 2020 Frustration, confusion and excitement: Mixed emotional responses to new household solar-battery systems in Australia. Energy Res. Soc. Sci. 70, 101656, https://doi.org/10.1016/j.erss.2020.101656

Romano, A.A., Scandurra, G., Cafora, A., Fodor, M. 2017. Renewable investments: the impact of green policies in developing and developed countries. Renew. Sustain. Energy Rev. 68, 738747. https://doi.org/10.1016/j.rser.2016.10.024

Sardianou, E., Genoudi, P., 2013. Which factors affect the willingness of consumers to adopt renewable energies? Renew. Energy 57, 1-4.

Schelly C., 2014. Residential solar electricity adoption: what motivates, and what matters? A case study of early adopters. Energy Res. Soc. Sci. 2, 183-191.

https://doi.org/10.1016/j.erss.2014.01.001

Sfeir, A.A., 1981. Solar radiation in Lebanon. Sol. Energy 26(6), 497-502. https://doi.org/10.1016/0038-092X(81)90160-2.

Shihadeh, A., Al Helou, M., Saliba, N., Jaber, S., Alaeddine, N., Ibrahim, E., Salahideh, Z., Chiit, M., 2013. The effect of distributed electric power generation on household exposure to airborne carcinogens in Beirut. Issam Fares Institute for Public Policy and International Affairs, American University of Beirut, Beirut.

https://www.aub.edu.lb/ifi/Documents/publications/research_reports/2012-

2013/20130207ifi rsr_cc effect\%20Diesel.pdf

Sigrin, B., Dietz, T., Henry, A., Ingle, A., Lutzenhiser, L., Moezzi, M., Spielman, S., Stern, P., Todd, A., Tong, J., Wolske, K., 2017. Understanding the Evolution of Customer Motivations and Adoption Barriers in Residential Solar Markets: Survey Data. National Renewable Energy Laboratory, USA. https://dx.doi.org/10.7799/1362095.

Smith, A., Raven, R., 2012. What is protective space? Reconsidering niches in transitions to sustainability. Res. Policy 41(6), 1025-1036. https://doi.org/10.1016/j.respol.2011.12.012

Sovacool, B.K., 2014. What are we doing here? Analyzing fifteen years of energy scholarship and proposing a social science research agenda. Energy Res. Soc. Sci. 1, 1-29.

https://doi.org/10.1016/j.erss.2014.02.003

Sun, Y., Hof, A., Wang, R., Liu, J., Lin, Y., Yang, D., 2013. GIS-based approach for potential analysis of solar PV generation at the regional scale: A case study of Fujian Province. Energ Policy 58, 248-259. https://doi.org/10.1016/j.proeng.2017.09.954

[dataset] Sunrise Sunset, 2019. Sunset and sunrise times. https://sunrise-sunset.org/

UNDP, 2018. Derisking Renewable Energy Investment - Lebanon. United Nations Development Program, Lebanon. 
https://www.lb.undp.org/content/lebanon/en/home/library/environment_energy/DeriskingRenewable-Energy-Investment-Lebanon1.html (accessed 2 October 2019)

UNDP, 2014. Photovoltaic Plants in Lebanon. Country Entrepreneurship for Distributed Renewables Opportunities. https://www.lb.undp.org/content/lebanon/en/home/library/environment_energy/photovoltaicpower-plants-in-lebanon.html (accessed 15 September 2020)

Verdeil, E., 2019. Securitisation of urban electricity supply: A political ecology perspective on the cases of Jordan and Lebanon, in: Yacobi, H., Nassara, M. (Eds.), Routledge Handbook on Middle Eastern Cities, Routledge, London, pp. 246-264. https://halshs.archivesouvertes.fr/halshs-02176158/document

Verdeil, E., 2018. Infrastructure crises in Beirut and the struggle to (not) reform the Lebanese State. Arab Stud. J. 16(1), 84-112. https://halshs.archives-ouvertes.fr/halshs-01854027/document

Verdeil, E., 2016. Beirut. The metropolis of darkness and the politics of urban electricity grid, in: Luque-Ayala, A., Silver, J. (Eds.), Energy, Power and Protest on the Urban Grid. Geographies of the Electric City. Routledge, London, pp. 155-175. https://halshs.archives-ouvertes.fr/halshs00858126/document

Zhang, Y., Ren, J., Pu, Y., and Wang, P., 2020. Solar energy potential assessment: A framework to integrate geographic, technological, and economic indices for a potential analysis. Renew. Energy 149, 577-586. https://doi.org/10.1016/j.renene.2019.12.071

\section{Appendix}

Table A-1: Impact of Solar PV lifespan on the NPV assessment

\begin{tabular}{|l|l|l|l|}
\hline Lifespan & $\begin{array}{l}\text { Percentage of Positive } \\
\text { NPV }\end{array}$ & Total NPV (USD) & $\begin{array}{l}\text { City Average NPV } \\
\text { (USD) }\end{array}$ \\
\hline $\begin{array}{l}20 \text { years (Baseline } \\
\text { Scenario) }\end{array}$ & 73 & 18166268 & 8272 \\
\hline 25 years & 76 & 21294640 & 9697 \\
\hline 30 years & 77 & 23237114 & 10582 \\
\hline
\end{tabular}

